\title{
Triple anticoagulation therapy in patients with atrial fibrillation undergoing percutaneous coronary intervention - real life assessment
}

\author{
Paweł Bogacki, Anna Kabłak-Ziembicka, Krzysztof Bryniarski, Leszek Wrotniak, Elżbieta Ostrowska-Kaim, \\ Krzysztof Żmudka, Tadeusz Przewłocki
}

Department of Interventional Cardiology, Institute of Cardiology, Jagiellonian University School of Medicine, The John Paul II Hospital, Krakow, Poland

Adv Interv Cardiol 2016; 12, 4 (46): 303-313

DOI: 10.5114/aic.2016.63629

\begin{abstract}
A bstract
Introduction: Triple anticoagulation therapy (TT), comprising dual antiplatelet therapy (DAPT) and oral anticoagulation (OAC), is essential in atrial fibrillation (AF) patients after percutaneous coronary intervention (PCI), but it increases the bleeding risk.

Aim: To assess TT models, in- and out-hospital bleeding and thromboembolic complications, and TT alterations.

Material and methods: During 12 months, consecutive AF post-PCI patients were scheduled for TT. Alterations in TT and thromboembolic events (death, myocardial infarction, ischemic stroke, in-stent thrombosis, peripheral embolization) were recorded. Major, non-major and minor bleeding episodes were assessed.

Results: One hundred and thirty-six out of 3171 patients, aged $73.0 \pm 8.4$ years (90 male), were included. Intra-hospitally, thrombotic events occurred in 9 (6.6\%), while bleeding events occurred in 71 (52.2\%) patients. Access-site hematoma and blood transfusions during in-hospital stay predisposed physicians to heparin administration as part of TT on discharge $(p=0.018$ and $p=0.033$ respectively). Eventually, DAPT plus warfarin or plus novel oral anticoagulant (NOAC) or plus low molecular weight heparin was prescribed in 72 (52.9\%), $53(39 \%)$, and $11(8.1 \%)$ patients, respectively. HAS-BLED and CHA2DS2-VASc scores were similar between subgroups ( $p=0.63$ and $p=0.64$ respectively). During $10.2 \pm 4.2$ months of follow-up, 11 (8.1\%) deaths, and 9 (6.6\%) non-fatal thromboembolic events occurred. Bleeding events occurred in $45(34.6 \%)$ patients, including 14 (10.3\%) major. TT was the only factor associated with increased risk of major bleeding $(18.6 \%$ vs. $4.2 \%, p=0.008)$. Early termination of any TT component, which concerned $59(45.4 \%)$ patients, did not increase the risk of thromboembolic events $(p=0.89)$.

Conclusions: Our study indicates that TT is associated with high mortality and bleeding rates in a relatively short period of time. Discontinuation of any TT drug did not increase the thromboembolic event rate, while it was associated with reduced risk of major bleeding.
\end{abstract}

Key words: atrial fibrillation, cardiovascular events, triple anticoagulant therapy, coronary percutaneous intervention, bleeding and thromboembolic complications.

\section{Introduction}

Atrial fibrillation (AF) is the most common arrhythmia, affecting an estimated 6 million Europeans [1], and it increases the risk of ischemic stroke (IS) five fold [1, 2]. Ischemic stroke of such etiology is proved to be associated with worse neurological outcomes compared to IS of other origin $[1,2]$. It is reported that about $20-30 \%$ of all AF patients suffer from coronary artery disease (CAD) $[3,4]$ and subsequently face the need of percutaneous coronary intervention $(\mathrm{PCl})$ with stent implantation. With $\mathrm{AF}$ being the most frequent indication for oral anticoagu- lation (OAC) and $\mathrm{PCl}$ resulting in the need of lengthy dual antiplatelet therapy (DAPT), triple therapy (TT) seems to be the right choice for AF patients undergoing PCI [5]. However, it is uncertain which type of OAC should be combined with DAPT in which patients. Currently, there are three types of OAC therapy: vitamin $\mathrm{K}$ antagonists (VKA, i.e. warfarin or acenocoumarol), novel OACs (NOACs, such as rivaroxaban, dabigatran or apixaban) and low molecular weight heparin (LMWH). There is little research available on how to guide the decision-making process regarding type of TT for individual patients. Moreover,

\section{Corresponding author:}

Paweł Bogacki MD, Department of Interventional Cardiology, Institute of Cardiology, Jagiellonian University School of Medicine, John Paul II Hospital, 80 Prądnicka St, 31-202 Krakow, Poland, phone: +48 667177 677, e-mail: pawelbogacki1@gmail.com Received: 28.06.2016, accepted: 30.07.2016. 
limited data have been published regarding real-life assessment of safety and efficacy of various forms of TT in clinical practice.

\section{Aim}

The study aimed to determine the real-life prevalence of patients on TT and to evaluate doctors' decisions on TT models (DAPT + VKA, DAPT + NOAC, DAPT + LMWH), as well as to assess in- and out-hospital bleeding and thromboembolic complications.

Additionally, the data regarding TT duration and any alterations to the anticoagulation regimen for each patient in the outpatient setting were analyzed.

\section{Material and methods}

\section{Study group}

Out of 3171 consecutive patients admitted to our department between 1.10.2014 and 30.09.2015, 163 (5.1\%) required TT. Twenty-one subjects were excluded due to participation in blinded anticoagulant drug trials and 6 due to mechanical valve prosthesis. Altogether, $136 \mathrm{pa}$ tients (mean age: $73.0 \pm 8.4$, range: $51-88$ years, 90 men) with either paroxysmal or permanent non-valvular AF admitted for stable angina (SA) or myocardial infarction (MI) who underwent $\mathrm{PCl}$ were retrospectively evaluated for bleeding and thromboembolic complications during the in-hospital period as well as during long-term follow-up. The DAPT was introduced or continued according to the guidelines on PCl. The DAPT in all study participants consisted of $75 \mathrm{mg}$ of aspirin and $75 \mathrm{mg}$ of clopidogrel daily. There were no patients taking ticagrelor or prasugrel. The mean weekly dosage of VKA was $29.7 \mathrm{mg}$, and the median weekly dosage was $28 \mathrm{mg}$. Seventy-three percent of patients taking rivaroxaban had a lower dose (15 mg q.d.) and $83 \%$ of patients taking dabigatran were on a lower dose (110 mg b.i.d.). Antithrombotic therapy was continued or introduced during hospitalization according to the guidelines on AF [1]. Thus, in all of these patients AF was the indication for VKA/NOAC, whereas $\mathrm{PCl}$ was the indication for DAPT.

Exclusion criteria were: valvular AF, participation in blinded anticoagulant drug trials, mechanical valve as indication for VKA, patients requiring coronary artery bypass grafting, and lack of patient consent.

The study participants were further divided according to their administered anticoagulation regimen during the in-hospital stay:

- group I consisted of 72 patients (age $73.3 \pm 7.7$ years, $70.8 \%$ male) with VKA as part of the TT;

- group II consisted of 53 patients (age $72.5 \pm 9.2$ years, $58.5 \%$ male) with NOAC as part of the TT;

- group III consisted of 11 patients (age $77.0 \pm 11.0$, $72.7 \%$ male) with LMWH as part of the TT.

The prevalence of conventional atherosclerosis risk factors (diabetes, hyperlipidemia, arterial hypertension, previous $\mathrm{MI}, \mathrm{PCl}$ or coronary artery bypass graft (CABG)), type of AF (paroxysmal vs. persistent) as well as baseline laboratory and angiographic results were recorded.

Follow-up stopped at the time of death or on May 1 , 2016, whichever came first. Data regarding in-hospital stay were gathered retrospectively based on medical records, whereas follow-up was performed in the form of phone surveys and dedicated hospital visits.

The study protocol was reviewed and approved by the local ethical committee. All the studied patients gave their informed consent for participation in the study. The study was performed in accordance with the Declaration of Helsinki.

\section{Atrial fibrillation and risk assessment}

Atrial fibrillation was diagnosed in accordance with the 2010 ESC guidelines [6]. Additionally, any trace of AF in medical documentation of the patient (either previous ECG exams or documented diagnosis) was considered sufficient to diagnose AF.

Bleeding and thrombotic risk was assessed individually for each patient using the standardized HAS-BLED and $\mathrm{CHA}_{2} \mathrm{DS}_{2}$-VASc scales $[6,7]$.

\section{Coronary angioplasty and PCI procedure}

Coronary angioplasty was performed from the radial or femoral vascular access using the Coroscop system (Siemens AG, Munich, Germany) equipped with Quantcor version 4.0 quantitative analysis software. The procedure was performed in accordance with widely accepted standards and rules. The details of the procedure such as predilatation before stenting, use of plaque preparation, AG rotablation or cutting balloon as well as use of bare-metal stents (BMS) or drug-eluting stents (DES) were left to the discretion of the leading physician.

\section{DAPT + OAC therapy duration}

Duration of TT was preplanned according to combined consensus guidelines from 2014 [8]. In brief, in the setting of $\mathrm{PCl}$ in patients with $\mathrm{SA}$, if BMS was implanted TT was recommended for at least 1 month with gastric protection, followed by OAC (INR 2.0-2.5 if VKA) provided that HAS-BLED is lower than 3. In the case of high HASBLED (3 or more), TT was recommended for 2-4 weeks, followed by OAC thereafter. When a $2^{\text {nd }}$ generation DES was implanted, TT was recommended for at least 3 months, followed by OAC and aspirin up to 12 months, then OAC (INR 2.0-3.0 if VKA) thereafter.

In the setting of $\mathrm{MI}$, in patients with low bleeding risk (HAS-BLED < 3) TT was recommended for at least 6 months followed by single antiplatelet therapy and low intensity OAC (INR 2.0-2.5 if VKA) up to 12 months, and then OAC thereafter (INR 2.0-3.0 if VKA).

In $\mathrm{MI}$ patients with high bleeding risk (HAS-BLED 3 or more), TT was recommended for 4 weeks, followed 
by single antiplatelet therapy and low intensity OAC (INR 2.0-2.5 if VKA) up to 12 months, and then OAC thereafter (INR 2.0-3.0 if VKA).

Concomitant use of PPI is recommended per guidelines for $\mathrm{Gl}$ protection $[8,9]$.

\section{TT termination}

Early termination was defined as the termination of any antiplatelet drug earlier than recommended by the treating cardiologist or termination of use of the anticoagulant drug at any point.

\section{Evaluation of bleeding complications}

The bleeding classification was adopted from Beyer-Westendorf et al., who divided bleeding into three categories: major, non-major clinically relevant (NMCR) and minor [10].

The following criteria for major bleeding in non-surgical patients were applied: fatal bleeding and/or symptomatic bleeding in a critical area or organ, such as intracranial, intraspinal, intraocular, retroperitoneal, intraarticular or pericardial, or intramuscular with compartment syndrome, and/or bleeding causing a fall in hemoglobin level of $2 \mathrm{~g} / \mathrm{l}$ or more, or leading to transfusion of two or more units of whole blood or red blood cells.

In brief, NMCR was defined as any non-major bleeding comprising hemodynamics or leading to hospitalization, as well as epistaxis, gingival bleeding, hemoptysis lasting more than $5 \mathrm{~min}$, macroscopic hematuria or any bleeding that had clinical consequences for the patient (i.e. medical intervention, unscheduled medical contact, temporary cessation of the drug).

Minor bleeding was defined as any overt bleeding not fulfilling the definition of major or NMCR bleeding [10].

\section{Evaluation of thrombotic and cardiovascular complications}

During the mean observation period of $10.2 \pm 4.2$ months the incidence of cardiovascular death (CVD), MI, IS, in-stent thrombosis and peripheral embolization was recorded.

Clinical classification of MI was adopted from Thygesen et al. [11]. Diagnosis of IS was established by a neurologist to ensure reliability. Cardiovascular death was defined as a fatal IS, fatal MI or other CVD (i.e. any sudden or unexpected death unless proven as non-cardiovascular on autopsy).

The criteria for stent thrombosis were adopted from an academic research consortium (ARC) [12].

\section{Statistical analysis}

Continuous variables are presented as mean \pm one SD, while categorical variables are expressed as frequencies and percentages. Means of analyzed parameters across groups were tested with the analysis of variance (ANOVA) test, and frequencies were compared by the $\chi^{2}$ test for independence.

The normal distribution of studied variables was determined by the Shapiro-Wilk test. Differences between mean values were verified using Student's $t$ test when the distribution of variables was normal, in other cases applying the Mann-Whitney $U$ test. Cumulative event-free survival Kaplan-Meier curves including overall event-free survival, death, thrombotic and major bleeding events were calculated for patients on active TT.

Statistical analyses were performed with Statistica 12.0 software. Statistical significance was assumed at $p<0.05$.

\section{Results}

\section{In-hospital period}

Out of 136 subjects with AF, the indication for coronary angiography with subsequent $\mathrm{PCl}$ was $\mathrm{MI}$ in 76 (55.9\%) and SA in 60 (44.1\%) patients (Table I). Balloon angioplasty alone was performed in $4(2.9 \%)$, a BMS was implanted in $6(4.4 \%)$, and a $2^{\text {nd }}$ generation DES in 118 $(86.8 \%)$ subjects. One-vessel $\mathrm{PCl}$ was performed in 100 (73.5\%), 2-vessel $\mathrm{PCl}$ in 24 (17.6\%) and 3-vessel $\mathrm{PCl}$ in $4(2.9 \%)$ patients. Out of the remaining 8 patients, 4 with an occluded target vessel and late presentation to the Emergency Department (ED) outside the therapeutic window, and 4 with multivessel disease were qualified for optimal medical treatment by the decision of a multidisciplinary Heart Team.

In-hospital thrombotic events occurred in 9 (6.6\%) patients. Out of those 9 patients 6 (66.6\%) were discharged on TT with VKA, 2 (22.2\%) on TT with NOAC and 1 (11.1\%) on TT with LMWH $(p=0.72)$. Detailed information on in-hospital thrombotic complications is shown in Table II.

Patients with acute coronary syndrome suffered more frequently from thrombotic complications during hospitalization than elective patients, although the difference was not statistically significant (9.5\% vs. $3.2 \%, p=0.15)$.

In-hospital bleeding occurred in 71 (52.2\%) of patients. Major, NMCR and minor bleeding occurred in 31 (22.8\%), 16 (11.8\%) and 45 (33.1\%) patients respectively. A detailed description of all in-hospital bleeding complications is provided in Table II.

In patients with access site hematoma, LMWH was significantly more frequently prescribed as part of TT as compared to other drugs $(27.3 \%$ vs. $5.1 \%$ in VKA and $1.9 \%$ in NOAC groups, $p=0.018$ ). Patients requiring blood transfusions during hospitalization were more likely to receive $\mathrm{LMWH}$ on discharge as part of TT, compared to other anticoagulants (18.2\% vs. $1.4 \%$ in VKA and $1.9 \%$ in NOAC groups, $p=0.033)$. Anticoagulant selection was mainly based on the risk of bleeding and prior complications on certain anticoagulation regimens (Table II).

On discharge, 72 (51\%) patients were assigned to TT including VKA + DAPT, 53 (39\%) received NOAC + DAPT, 
Table I. Baseline patient characteristics. Urgent admission was associated with prescribing LMWH as part of TT on discharge. Patients on VKA had significantly higher INR than non-VKA patients

\begin{tabular}{|c|c|c|c|c|c|}
\hline Parameter & $\begin{array}{c}\text { Overall } \\
(n=136)\end{array}$ & $\begin{array}{l}\text { Group 1 } \\
(n=72)\end{array}$ & $\begin{array}{l}\text { Group } 2 \\
(n=53)\end{array}$ & $\begin{array}{l}\text { Group } 3 \\
(n=11)\end{array}$ & ANOVA between subgroups \\
\hline Atrial fibrillation: & & & & & 0.300 \\
\hline Paroxysmal & $93(68.4)$ & $46(63.9)$ & $38(71.7)$ & $9(81.8)$ & \\
\hline Permanent & $43(31.6)$ & $26(31.1)$ & $15(28.3)$ & $2(18.2)$ & \\
\hline $\mathrm{CHA}_{2} \mathrm{DS}_{2}$-VASc [points] & $4.4 \pm 1.6$ & $4.3 \pm 1.3$ & $4.4 \pm 1.9$ & $4.8 \pm 1.3$ & 0.641 \\
\hline Median & 4 & 4 & 4 & 5 & \\
\hline HAS-BLED [points] & $2.5 \pm 0.9$ & $2.5 \pm 0.8$ & $2.5 \pm 1.0$ & $2.7 \pm 0.8$ & 0.639 \\
\hline Median & 2 & 2 & 2 & 3 & \\
\hline Age [years] & $73.3 \pm 8.6$ & $73.3 \pm 7.7$ & $72.5 \pm 9.2$ & $77.0 \pm 11.0$ & 0.286 \\
\hline Sex (male) & $90(66.2)$ & $54(70.8)$ & $31(58.5)$ & $8(72.7)$ & 0.315 \\
\hline Admission: & & & & & 0.048 \\
\hline Urgent (ACS) & $76(55.9)$ & $37(54.4)$ & $29(54.7)$ & $10(90.9)$ & \\
\hline Planned (SA) & $60(44.1)$ & $35(48.6)$ & $24(45.3)$ & $1(9.1)$ & \\
\hline \multicolumn{6}{|l|}{ Risk factors: } \\
\hline Hypertension & $129(94.9)$ & $69(95.8)$ & $49(92.5)$ & $11(100.0)$ & 0.506 \\
\hline Hyperlipidemia & $119(87.5)$ & $64(88.9)$ & $44(83.0)$ & $11(100.0)$ & 0.263 \\
\hline Diabetes mellitus & $58(42.6)$ & $33(45.8)$ & $22(41.5)$ & $3(27.3)$ & 0.499 \\
\hline Previous MI & $65(47.8)$ & $34(47.2)$ & $22(41.5)$ & $9(81.8)$ & 0.051 \\
\hline Previous PCl & $53(39.0)$ & $31(43.1)$ & $17(32.1)$ & $5(45.5)$ & 0.415 \\
\hline Previous CABG & $23(16.9)$ & $15(20.8)$ & $7(13.2)$ & $1(9.1)$ & 0.410 \\
\hline \multicolumn{6}{|l|}{ Laboratory data: } \\
\hline Creatinine $[\mathrm{mg} / \mathrm{dl}]$ & $106.3 \pm 71.0$ & $115.0 \pm 94.1$ & $91.9 \pm 20.8$ & $117.1 \pm 27.7$ & 0.176 \\
\hline eGFR $\left[\mathrm{ml} / \mathrm{min} / 1.73 \mathrm{~m}^{2}\right]$ & $66.4 \pm 19.8$ & $66.0 \pm 22.5$ & $69.2 \pm 14.9$ & $55.7 \pm 18.9$ & 0.118 \\
\hline $\mathrm{HGB}[\mathrm{g} / \mathrm{dl}]$ & $13.5 \pm 1.4$ & $13.5 \pm 1.2$ & $13.5 \pm 1.5$ & $13.0 \pm 2.2$ & 0.448 \\
\hline $\mathrm{PLT}\left[10^{9} / \mathrm{l}\right]$ & $214.2 \pm 62.4$ & $210.5 \pm 56.5$ & $224.5 \pm 67.5$ & $189.4 \pm 70.3$ & 0.180 \\
\hline INR & $1.4 \pm 0.6$ & $1.6 \pm 0.7$ & $1.1 \pm 0.2$ & $1.2 \pm 0.4$ & $<0.001$ \\
\hline \multicolumn{6}{|l|}{ Angiographic information: } \\
\hline Vessels with > 50\% DS & $2.4 \pm 1.4$ & $2.3 \pm 1.4$ & $2.4 \pm 1.3$ & $2.7 \pm 1.1$ & 0.691 \\
\hline \multicolumn{6}{|l|}{ Type of procedure: } \\
\hline $\mathrm{PCl}+\mathrm{POBA}$ & $4(2.9)$ & $1(1.4)$ & $3(5.7)$ & $0(0)$ & 0.314 \\
\hline $\mathrm{PCl}+$ limus-DES & $118(86.8)$ & $62(86.1)$ & $45(84.9)$ & $11(100)$ & 0.307 \\
\hline $\mathrm{PCl}+\mathrm{BMS}$ & $6(4.4)$ & $3(4.2)$ & $3(5.7)$ & $0(0)$ & 0.700 \\
\hline OMT & $8(5.9)$ & $5(6.9)$ & $3(5.7)$ & $0(0)$ & 0.657 \\
\hline No. of implanted stents & $1.3 \pm 0.6$ & $1.2 \pm 0.6$ & $1.5 \pm 0.8$ & $1.0 \pm 0.5$ & 0.060 \\
\hline Length of stents & $26.5 \pm 17.8$ & $23.6 \pm 1.4$ & $31.2 \pm 22.4$ & $22.4 \pm 14.8$ & 0.066 \\
\hline
\end{tabular}

Values are means $\pm S D$ or $n(\%)$. BMS - bare-metal stent, DES - drug-eluting stent, CABG - coronary artery bypass graft, eGFR - estimated glomerular filtration rate, HGB - hemoglobin, INR - international normalized ratio, LMWH - low molecular weight heparin, MI - myocardial infarction, PCI - percutaneous coronary intervention, PLT - platelets, POBA - plain old balloon angioplasty, OMT - optimal medical treatment, TT - triple therapy, VKA - vitamin K antagonist. Group 1 comprises patients with warfarin/acenocoumarol; group 2 comprises patients with rivaroxaban/dabigatran; group 3 comprises patients with low molecular weight heparin. 
Table II. In-hospital thrombotic and bleeding complications grouped by type of anticoagulation drug patient received as part of TT on discharge. Blood transfusion and access site hematoma predisposed to prescribing LMWH on discharge (group 3)

\begin{tabular}{|c|c|c|c|c|c|}
\hline Parameter & $\begin{array}{c}\text { Total } \\
(n=136)\end{array}$ & $\begin{array}{l}\text { Group } 1 \\
(n=72)\end{array}$ & $\begin{array}{l}\text { Group } 2 \\
(n=53)\end{array}$ & $\begin{array}{l}\text { Group } 3 \\
(n=11)\end{array}$ & $\begin{array}{c}\text { Fisher's exact test } \\
\text { between subgroups, } p\end{array}$ \\
\hline Thrombotic complications: & $9(6.6)$ & $6(8.4)$ & $2(3.8)$ & $1(9.1)$ & 0.480 \\
\hline Thrombus in heart chambers & $5(3.7)$ & $3(4.2)$ & $1(1.9)$ & $1(9.1)$ & 0.346 \\
\hline In-stent thrombosis & $3(2.2)$ & $3(4.2)$ & $0(0)$ & $0(0)$ & 0.428 \\
\hline$\overline{P E}$ & $1(0.7)$ & $0(0)$ & $1(1.9)$ & $0(0)$ & 0.471 \\
\hline Major bleeding: & $31(22.8)$ & & & & \\
\hline GI bleeding & $7(5.1)$ & $3(4.2)$ & $2(3.7)$ & $2(18.2)$ & 0.152 \\
\hline Hg drop > 2 g/l & $27(19.8)$ & $10(13.9)$ & $14(26.4)$ & $3(27.3)$ & 0.172 \\
\hline Transfusion & $4(2.9)$ & $1(1.4)$ & $1(1.9)$ & $2(18.2)$ & 0.033 \\
\hline NMCR bleeding: & $16(11.8)$ & & & & \\
\hline Access site hematoma & $11(8.1)$ & $7(5.1)$ & $1(1.9)$ & $3(27.3)$ & 0.018 \\
\hline Hematuria & $7(5.1)$ & $3(4.2)$ & $3(5.7)$ & $1(9.1)$ & 0.476 \\
\hline URT bleedings & $4(2.9)$ & $1(1.4)$ & $2(3.8)$ & $1(9.1)$ & 0.277 \\
\hline Minor bleeding: & $45(33.1)$ & & & & \\
\hline Nosebleeds & $36(26.5)$ & $20(27.8)$ & $13(24.5)$ & $3(27.3)$ & 0.956 \\
\hline Other & $13(9.6)$ & $9(12.5)$ & $4(7.5)$ & $0(0)$ & 0.602 \\
\hline
\end{tabular}

Values are $n$ (\%). Other minor bleeding complications included microscopic hematuria and bruising. TT - triple therapy, VKA - vitamin K antagonist, DAPT - dual antiplatelet therapy, NOAC - novel oral anticoagulant, LMWH - low molecular weight heparin, PE - pulmonary embolism, GI - gastrointestinal, Hg - hemoglobin, URT - upper respiratory tract. Group 1 comprises patients with warfarin/acenocoumarol; group 2 comprises patients with rivaroxaban/dabigatran; group 3 comprises patients with low molecular weight heparin.

and the remaining 11 (8.7\%) were given $L M W H+$ DAPT. The $\mathrm{CHA}_{2} \mathrm{DS}_{2}$-VASC and HAS-BLED scores were similar across the study subgroups $(p=0.64$ and $p=0.64$ respectively) and are shown in Table I.

Baseline and periprocedural characteristics were similar between the groups discharged on various forms of TT (Table I). Patients admitted for MI with in-hospital bleeding complications were more likely to be given LMWH as part of TT than other anticoagulation drugs, but the difference is not statistically significant $(18.2 \%$ vs. $8.3 \%$ vs. $3.8 \%$ respectively, $p=0.23$ ).

\section{TT modifications after hospital discharge}

Within 1 month after discharge, among the $11 \mathrm{pa}$ tients discharged on LMWH + DAPT, the initial TT was replaced by VKA + DAPT in 5 and by NOAC + DAPT in 4 . Two patients remained on $\mathrm{LMWH}+\mathrm{DAPT}$ indefinitely.

On follow-up, 87 (66.9\%) patients reported some sort of alteration in their antithrombotic regimen. Out of those, 11 (8.5\%) reported a switch of one antithrombotic drug for another. Detailed information on drug switches is described in Figure 1. Seventy-six (58.5\%) patients terminated TT: 59 (45.4\%) prematurely and 17 (13.1\%) as recommended by the treating cardiologist. Detailed information on alterations in the TT including time of ter-

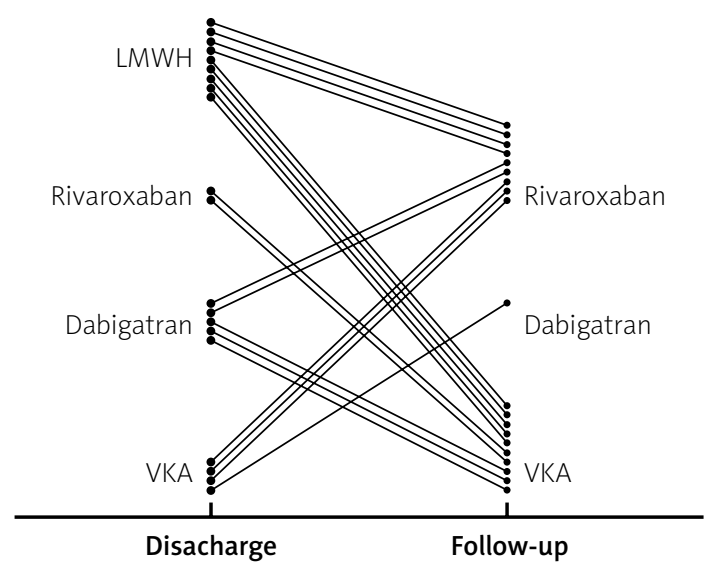

Figure 1. Switches between anticoagulation drugs. Each line represents 1 patient. Three patients switched from dabigatran to VKA (1 - mechanical valve, 1 - financial reasons, 1 - unknown reasons), 3 switched from VKA to rivaroxaban (2 - labile INR, 1 - enrolled in a rivaroxaban drug trial), 2 switched from dabigatran to rivaroxaban (1 - allergic reaction to dabigatran, 1 - unknown reasons), 2 switched from rivaroxaban to VKA (1 - bleeding complications, 1 - unknown reasons) and 1 switched from VKA to dabigatran (unknown reasons)

LMWH - low molecular weight heparin, VKA - vitamin K antagonists. 
mination, number of drugs terminated and type of drugs terminated is presented in Figure 2.

\section{Thrombotic and bleeding complications in the follow-up period}

The mean follow-up was $10.2 \pm 4.2$ months (range: 3-18). Detailed information about final antithrombotic regimens was available for 130 (95.6\%) of the patients. Six (4.6\%) were lost to follow-up (5 from the VKA group,

\section{A}
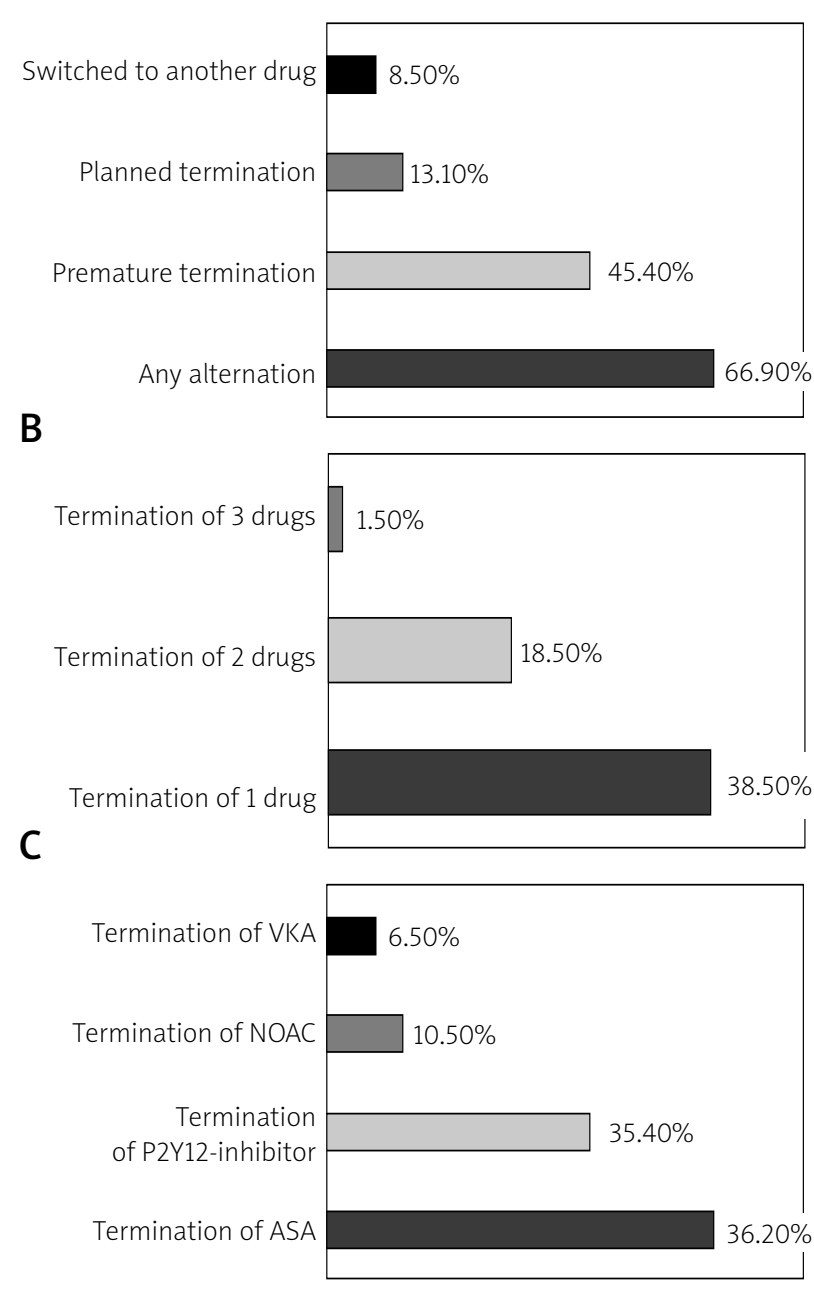

Figure 2. Alterations in therapy. A - any alternation (87 patients, 66.9\%), premature termination (59 patients, 45.4\%), planned termination (17 patients, 13.1\%) and switch to another drug (11 patients, $8.5 \%$ ). B - termination of 1 drug (50 patients, $38.5 \%$ ), 2 drugs (24 patients, $18.5 \%$ ) or 3 drugs (2 patients, $1.5 \%$ ). C - termination of ASA (47 patients, 36.2\%), P2Y12 inhibitors (46 patients, $35.4 \%$ ), VKA (5 patients, $6.5 \%$ ) and NOAC (6 patients, 10.5\%). Seventy-two patients had VKA prescribed and 55 patients had NOAC prescribed

ASA - acetylsalicylic acid, NOAC - novel oral anticoagulant, VKA - vitamin K antagonist.
1 from the NOAC group), but according to the national Medical Insurance Database (eWUŚ) they were alive and no hospital admissions were recorded as of March $1^{\text {st }}$, 2016.

During follow-up, thrombotic events occurred in 16 (12.3\%) patients, any bleeding (major, NMCR and minor) occurred in 45 (34.6\%). Eleven (8.5\%) deaths were recorded. Seven of them resulted from thrombotic complications (2 mesenteric emboli, 3 Mls, 2 sudden cardiac deaths), 1 from bleeding complication (ICH) and 3 from other causes (1 pneumonia, 1 cardio-respiratory insufficiency, 1 sudden, not well-determined death).

Nine (6.9\%) non-fatal thrombotic complications were observed (1 IS, 7 MIs and $1 \mathrm{PE}$ ).

Out of 10 patients who suffered an Ml during follow-up, in-stent thrombosis occurred in 7 (according to the adopted definition, 6 were definite and 1 was possible).

There was no significant difference in the occurrence of thrombotic complications between patients on various forms of TT (Table III).

Interestingly, only 4 out of 10 Mls occurred in patients who had terminated any of the TT drugs prematurely: 3 in patients who had terminated any antiplatelet agent and 1 in a patient who terminated OAC (Table IV). There was no significant difference in occurrence of $\mathrm{MI}$ between patients who terminated any TT drug prematurely and those who did not $(6.8 \%$ vs. $8.5 \%, p=0.72)$. One IS was recorded and it occurred in a patient who had terminated the use of ASA prematurely and subsequently switched from rivaroxaban to dabigatran due to an allergic reaction. We noted no significant difference in the appearance of any thrombotic (both fatal and non-fatal) complication between those patients who terminated any of the drugs prematurely and those who did not (11.9\% vs. $12.7 \%, p=0.54)$, as well as between subgroups of patients on various forms of TT (Table IV).

The number of any bleeding events (major, NMCR and minor) was 45 (34.6\%). The frequency of any bleeding was not different between patients who prematurely terminated any of the drugs as compared to those who did not. Fourteen major bleeding events ( 6 GI, 6 URT and $2 \mathrm{ICH}$, one of which was fatal) were recorded. All major bleeding complications appeared in patients actively taking all three drugs, and there was a significant difference in the major bleeding occurrence between those patients who continued TT vs. those who terminated any of the drugs prematurely ( $18.6 \%$ vs. $4.2 \%, p=0.008)$. Additionally, 13 (10\%) NMCR bleeding events occurred. There is no statistically significant difference in the occurrence of NMCR in patients who terminated any of the TT drug vs. those who did not ( $8.4 \%$ vs. $11.2 \%, p=0.60)$. Minor bleeding occurred in $32(24.6 \%)$ patients and included bruising, trace of blood on handkerchief, and prolonged bleeding after a small injury. No significant difference in 
Table III. Thrombotic and bleeding complications during long-term observation grouped by type of anticoagulation drug patient received as part of TT. Group 1 patients had a significantly higher rate of PE compared to group 2 patients

\begin{tabular}{|c|c|c|c|c|c|c|}
\hline Parameter & $\begin{array}{c}\text { Total } \\
(n=136)\end{array}$ & $\begin{array}{l}\text { Group } 1 \\
(n=77)\end{array}$ & $\begin{array}{l}\text { Group } 2 \\
(n=57)\end{array}$ & $\begin{array}{c}\text { Group } 3 \\
(n=2)\end{array}$ & $\begin{array}{l}\chi^{2} \text { group } 1 \\
\text { vs. group } 2\end{array}$ & $\begin{array}{c}\text { Fisher's exact test } \\
\text { between subgroups, } p\end{array}$ \\
\hline Thrombotic complications: & $16(11.8)$ & $11(14.3)$ & $5(8.8)$ & $0(0)$ & 0.330 & 0.552 \\
\hline MI & $10(7.4)$ & $6(7.8)$ & $4(7.0)$ & $0(0)$ & 0.866 & 0.999 \\
\hline In-stent thrombosis & $7(5.1)$ & $5(6.5)$ & $2(3.5)$ & $0(0)$ & 0.443 & 0.729 \\
\hline IS & $1(0.7)$ & $0(0)$ & $1(1.8)$ & $0(0)$ & 0.243 & 0.434 \\
\hline PE & $5(3.7)$ & $5(6.5)$ & $0(0)$ & $0(0)$ & 0.050 & 0.139 \\
\hline Bleeding: & $45(33.1)$ & $28(36.4)$ & $17(29.8)$ & $0(0)$ & 0.428 & 0.519 \\
\hline Major & $14(10.3)$ & $10(13.0)$ & $4(7.0)$ & $0(0)$ & 0.246 & 0.512 \\
\hline NMCR & $13(9.6)$ & $9(11.7)$ & $4(7.0)$ & $0(0)$ & 0.366 & 0.637 \\
\hline Minor & $32(23.5)$ & $18(23.4)$ & $14(24.6)$ & $0(0)$ & 0.874 & 0.999 \\
\hline
\end{tabular}

Values are $n(\%)$. TT - triple therapy, MI - myocardial infarction, IS - ischemic stroke, PE - peripheral embolism (including mesenteric embolism - pulmonary embolism), NMCR - non-major clinically relevant. Group 1 comprises patients with warfarin/acenocoumarol, group 2 comprises patients with rivaroxaban/dabigatran, group 3 comprises patients with low molecular weight heparin.

minor bleeding events was found between patients who terminated any TT drug prematurely vs. those who did not $(25.4 \%$ vs. $23.9 \%, p=0.85)$.

Cumulative event-free survival Kaplan-Meier curves showed the overall event-free survival of $96.1 \%$ at 1 month and $67.2 \%$ at 6 months in patients on active TT (Figure 3). The respective 1- and 6-month survival free from death were $100 \%$ and $89.1 \%$, from thrombotic events $99.2 \%$ and $85.9 \%$, and from major bleeding $96.9 \%$ and $84.4 \%$ (Figure 3).

\section{Discussion}

The present study was designed to assess the safety and complication rate of $\mathrm{TT}$ in patients with $\mathrm{AF}$ and $\mathrm{PCl}$

Table IV. Thrombotic and all fatal complications grouped by premature termination of various TT drugs. Early termination of any TT drug was associated with lower risk of major bleeding

\begin{tabular}{|c|c|c|c|c|c|c|c|c|}
\hline Parameter & $\begin{array}{c}\text { Total } \\
N=130\end{array}$ & $\begin{array}{c}\text { Premature } \\
\text { termination } \\
\text { of any AA } \\
51(39.2) \\
\end{array}$ & $\begin{array}{c}\text { No premature } \\
\text { termination } \\
\text { of any AA } \\
79(60.8)\end{array}$ & $\begin{array}{c}P \text {-value } \\
\chi^{2}\end{array}$ & $\begin{array}{c}\text { Premature } \\
\text { termination } \\
\text { of OAC } \\
5(3.8) \\
\end{array}$ & $\begin{array}{c}\text { No premature } \\
\text { termination } \\
\text { of OAC } \\
125(96.2) \\
\end{array}$ & $\begin{array}{c}P \text {-value } \\
\chi^{2}\end{array}$ & $\begin{array}{c}P \text {-value } \\
\text { between } \\
\text { subgroups* }\end{array}$ \\
\hline All deaths: & $11(8.5)$ & $3(5.9)$ & $8(10.1)$ & 0.396 & $0(0)$ & $11(8.8)$ & 0.488 & 0.750 \\
\hline Thrombotic & $7(5.4)$ & $3(5.9)$ & $4(5.1)$ & 0.840 & $0(0)$ & $7(5.6)$ & 0.586 & 0.999 \\
\hline Bleeding & $1(0.8)$ & $0(0)$ & $1(1.3)$ & 0.420 & $0(0)$ & $1(0.8)$ & 0.841 & 0.999 \\
\hline Other & $3(2.3)$ & $0(0)$ & $3(3.8)$ & 0.159 & $0(0)$ & $3(2.4)$ & 0.726 & 0.443 \\
\hline $\begin{array}{l}\text { Thrombo-embolic } \\
\text { complications: }\end{array}$ & $16(12.3)$ & 6 (11.8) & $10(12.7)$ & 0.880 & $1(20)$ & $15(12)$ & 0.593 & 0.999 \\
\hline $\mathrm{Ml}$ & $10(7.7)$ & $3(5.9)$ & $7(8.9)$ & 0.534 & $1(20)$ & $9(7.2)$ & 0.291 & 0.649 \\
\hline $\begin{array}{l}\text { In-stent } \\
\text { thrombosis }\end{array}$ & $7(5.4)$ & $2(3.9)$ & $5(6.3)$ & 0.553 & $0(0)$ & $7(5.6)$ & 0.586 & 0.841 \\
\hline IS & $1(0.8)$ & $1(2.0)$ & $0(0)$ & 0.212 & $0(0)$ & $1(0.8)$ & 0.841 & 0.454 \\
\hline$\overline{P E}$ & $5(3.8)$ & $2(3.9)$ & $3(3.8)$ & 0.971 & $0(0)$ & $5(4)$ & 0.648 & 0.999 \\
\hline Bleeding: & 45 (34.6) & 19 (37.3) & 26 (32.9) & 0.611 & $3(60)$ & $42(33.6)$ & 0.224 & 0.247 \\
\hline Major & 14 (10.8) & $6(11.8)$ & 8 (10.1) & 0.769 & $0(0)$ & $14(11.2)$ & 0.428 & 0.001 \\
\hline NMCR & $13(10)$ & $5(9.8)$ & $8(10.1)$ & 0.952 & $0(0)$ & $13(10.4)$ & 0.447 & 0.406 \\
\hline Minor & $32(24.6)$ & $13(25.5)$ & 19 (24.1) & 0.852 & $3(60)$ & 29 (22.3) & 0.061 & 0.999 \\
\hline
\end{tabular}

Values are $n$ (\%). AA - antiplatelet agent, OAC - oral anticoagulant, MI-myocardial infarction, IS - ischemic stroke, PE - peripheral embolism. ${ }^{*}$ Fisher's exact test between groups of patients who terminated any antiplatelet agent prematurely vs. those who terminated OAC prematurely vs those who terminated any antiplatelet agent and OAC prematurely. 


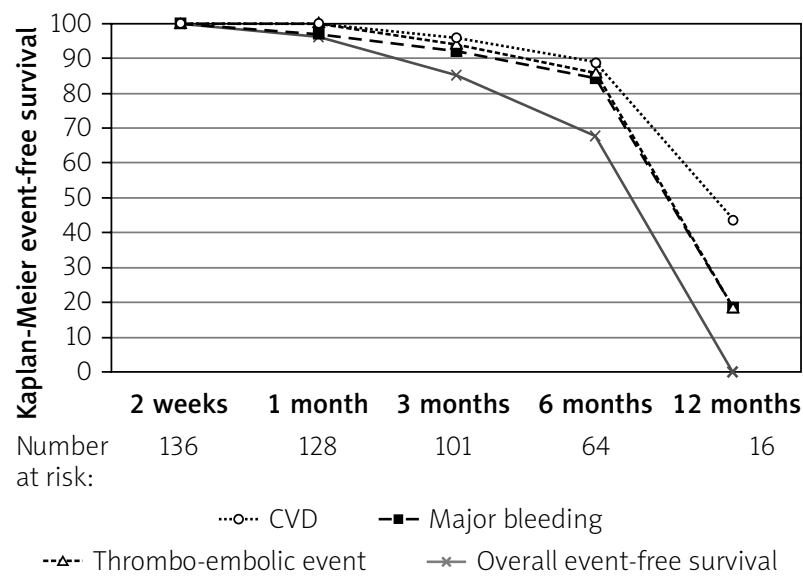

Figure 3. Kaplan-Meier curves showing event-free survival of patients on active triple therapy (TT). No patients with TT lasting 12 months were free from complications

recruited consecutively between October $1^{\text {st }} 2014$ and September $30^{\text {th }} 2015$, whose anticoagulation regimen on discharge was prescribed following the recent 2014 ESC guidelines on $\mathrm{AF}$ in patients presenting with $\mathrm{MI}$ and/or undergoing $\mathrm{PCl}[8]$.

Similarly to other studies, in the present one approximately $5 \%$ of the patients undergoing $\mathrm{PCl}$ have been receiving OAC for $\mathrm{AF}[4,13-15]$. That is a significant group of patients, yet it remains unclear how to treat them in terms of both peri-procedural and long-term anticoagulation. Out of 136 recruited subjects with AF, approximately a half presented with $\mathrm{MI}$ on admission. The optimal anticoagulant strategy in these patients is also unknown, and little research has been published on this matter [4, 16-18].

\section{OAC selection as a part of TT following PCI}

In our study no clear pattern was observed in terms of assigning a patient to a certain type of TT. In-hospital bleeding complications in the form of access-site hematoma and need for blood transfusions significantly more frequently guided physicians to give patients $L M W H$ on discharge. Most patients discharged on LMWH were reassigned for VKA or NOAC during 4 weeks following discharge. We did not determine any other statistically significant predictors for choosing particular OAC as part of TT. We rather conclude that, with the guidelines being vague in this regard, the decision of the type of antithrombotic drug as part of TT is left to the discretion of the leading physician and the preference of the patient, and LMWH seems to be considered by cardiologists as a safer option in patients with in-hospital bleeding complications.

The convenience of NOACs with fixed oral dosing and no need to monitor the anticoagulation effect, as well as very few interactions with other drugs or food products, seems to be a better choice for most patients, but in Polish reality NOACs are still associated with a significantly higher monthly cost of the therapy compared to VKA, and that could be the reason why only about $40 \%$ of the patients were given NOACs. We believe that the patient's preference was a major factor in the decision-making process.

Older guidelines prefer BMS implantation (particularly over first generation DES) in TT patients to shorten the necessity of TT [6]; however, this attitude faces serious limitations related to high risk of recurrent stenosis approaching $44 \%$ in patients with diabetes, renal failure, infection, $\mathrm{PCl}$ in small coronary vessels, long lesions and bifurcations [19]. Therefore, the probable benefit gained from the short period of TT in this group of patients is significantly limited by the restenosis rate. On the other hand, $2^{\text {nd }}$ generation DES have a favorable outcome in terms of restenosis and a relatively short period of required TT (3-6 months). The Biolimus DES introduced recently allows an even shorter time of TT. In a LEADERS Free ACS Study comparing the Biolimus DES with a BMS, at 12-month follow-up, treatment with the Biolimus DES was more effective (clinically driven target-lesion revascularization 3.9 vs. $9.0 \%, p=0.009$ ) and safer (cumulative incidence of cardiac death, $\mathrm{MI}$, or definite or probable stent thrombosis 9.3 vs. $18.5 \%, p=0.001)$, with significantly lower rates of cardiac mortality (3.4 vs. $6.9 \%, p=$ 0.049 ) and MI (6.9 vs. $13.8 \%, p=0.005)$ [20].

There is still a gap in the guidelines concerning MI patients left without $\mathrm{PCl}$ and qualified for optimal medical treatment. In the present study 8 patients were included in the analysis even though no $\mathrm{PCl}$ was performed - they were all AF patients admitted for $\mathrm{MI}$ in which TT was implemented and were facing the same risks of TT as the rest of the cohort. According to guidelines on STEMI [21], DAPT should be administered for up to 12 months in these patients. The recent guidelines do not address that issue [8].

\section{Long-term observation}

Faza et al. [22] observed that in median 4 months follow-up $26.7 \%$ out of 999 patients developed bleeding on TT (defined as at least $3 \mathrm{~g} / \mathrm{dl}$ hemoglobin drop). Our study showed a slightly higher number of bleeding complications (34.6\% of any bleeding) noted in longer follow-up, but a broader definition of bleeding was adopted. In a meta-analysis [23] of 9 studies comparing TT to DAPT alone, the authors found that the latter was correlated with much lower bleeding complications during 1 -year follow-up ( $O R=0.51$ for major bleeding). No difference in thrombotic event rate was found.

With regard to all bleeding, as well as major, NMCR and minor, we did not find any significant differences across different TT schemes in our study. The fact of TT itself was the major risk factor for major bleeding. More- 
over, the fact of early discontinuation of any anticoagulant was associated with the reduction of major bleeding incidents, and had no impact on thrombotic event occurrence. Indeed, the early termination of any component of TT was frequent and concerned about $45 \%$ of patients, including ASA termination in 36.2\%, P2Y12 inhibitor in $35.4 \%$, VKA in $6.5 \%$ and NOAC in $10.5 \%$ of patients.

Moreover, D'Ascenzo et al. compared 6 studies in which OAC + clopidogrel + ASA or OAC + clopidogrel was used. OAC + clopidogrel was associated with a major reduction of bleeding without affecting the rate of thrombotic events [23].

In another study concerning older patients with AF and $\mathrm{MI}$ undergoing $\mathrm{PCl}$, TT was associated with greater risk of bleeding requiring hospitalization $(H R=1.61)$ as well as ICH $(H R=2.04)$. Risk of thrombotic events was similar in both groups [24].

In a Danish registry [25], 315 (0.8\%) out of 40812 patients admitted due to $\mathrm{MI}$ were on $\mathrm{TT}$. The yearly incidence of bleeding was $12.0 \%$ for TT, whereas it was $3.7 \%$ for aspirin with clopidogrel and $2.6 \%$ for aspirin alone. In a recent study, Constantinos et al. did not find any differences in bleeding risk in patients with TT lasting 1 month as compared to TT longer than 1 month [26]. In a large nationwide registry of 40812 patients hospitalized with $\mathrm{Ml}$, the risk of subsequent hospitalizations for bleeding increased with the number of antithrombotic drugs used, being 1.8-fold in patients on VKA and aspirin, 3.5-fold in patients on VKA and clopidogrel, and 4-fold in patients on TT, with numbers needed to harm of $45.4,15.2$, and 12.5 , respectively [3, 25]. Our study showed a significant increase in risk of major bleeding on continuous TT compared to patients who had terminated any TT drug $(p=0.008)$.

The data above may lead to an assumption that the risks of continuing TT for more than 1 month may outweigh the benefits and should be individually considered. This is reflected in the latest ESC guidelines suggesting shortening the TT to a minimum by discontinuing one antiplatelet agent, which in most cases could be reduced to 1 month. The other recommendations include: the use of new generation DES as preferred over BMS, avoidance of novel $\mathrm{P}_{2} \mathrm{Y}_{12}$ inhibitors (prasugrel, ticagrelor) as part of DAPT, the use of the radial artery as the preferred access site, and broad use of PPIs to reduce the risk of GI bleeding $[5,8]$. In patients who had been taking OAC before $\mathrm{PCl}$, the drug they had been using should be continued as part of TT. If VKA is part of TT, the recommended INR should be within 2.0-2.5 for the time of TT with the therapeutic range $>70 \%$. If NOAC is the drug of choice, a reduced dose of NOAC (i.e. $110 \mathrm{mg}$ dabigatran BID, $15 \mathrm{mg}$ rivaroxaban $\mathrm{OD}$ ) should be prescribed for the duration of TT $[8,27]$.

As proven above, this group of patients is particularly challenging, as they remain at high risk of thrombotic complications both because of AF and the implemented stent and they should be adequately protected. The pathophysiology of clot formation in the fibrillating atrium (low sheer stress) is believed to be different from the formation of a clot within the stent (high sheer stress). Research shows that serum clotting factors play the leading role in clot formation in an AF setting, whereas platelet activation is believed to be crucial in formation of thrombus within the stent $[25,28-31]$. Therefore it seems necessary to merge OAC therapy with DAPT in those patients. Our study showed that patients taking NOACs as part of TT are better protected from peripheral embolism than those on VKA. This reflects similar findings in pivotal NOAC trials such as RE-LY with dabigatran (relative risk of primary outcome in the form of stroke or systemic embolism for higher dose dabigatran vs. VKA 0.66, 95\% Cl: 0.53-0.82) and ROCKET-AF with rivaroxaban (hazard of primary outcome in form of stroke or systemic embolism for rivaroxaban vs VKA 0.79; $95 \% \mathrm{Cl}$ : $0.66-0.96)[32,33]$.

Indeed, the most unfavorable combination of TT was VKA + DAPT, which was associated with higher risk of peripheral embolic events. The possible explanation of this phenomenon might be an insufficient therapeutic target for VKA with recommended INR 2.0-2.5, labile INR and patients' compliance. Interestingly, VKA is still preferred over NOACs by US guidelines in the setting of AF and $\mathrm{PCI}$ [34].

\section{Study limitations}

The study was performed retrospectively, which posed challenges in regard to data quality and consistency. The follow-up period is relatively short, and the number of study participants is small. For the majority of endpoints the power of the study is limited.

Moreover, the TT in studied patients was introduced at different stages of the disease - some were admitted to our department and had already been taking an anticoagulation drug, whereas others were treatment naïve and only started the TT during or after hospitalization. To eliminate bias stemming from the above-mentioned differences, a prospective study would be of value. The study did not analyze the time in therapeutic range (TTR) in patients taking VKA; thus effective anticoagulation was not documented.

\section{Conclusions}

Our real-life all-comers evaluation showed that about $5 \%$ of patients undergoing $\mathrm{PCl}$ required TT. There is still a lot of uncertainty and inconsistency in terms of the optimal management of the patients. The 10-month mortality of those patients was high (in our study $8.1 \%$ ), and so was the thrombotic event rate (12.3\%). Nevertheless, the occurrence of thrombotic events does not seem to be related to premature termination of any antiplatelet agents. Over $30 \%$ of patients suffered from bleeding complications, and continuation of TT was associated with a higher rate of major bleeding. A substantial num- 
ber of patients reported alterations to their TT, with as many as $44.6 \%$ of the patients terminating their therapy prematurely for various reasons. Our study has a relatively short follow-up period, and the number of study participants is not big enough, so further research is needed on this subject to gather more data that would help determine the right way of treating these very challenging, high-risk patients.

\section{Conflict of interest}

The authors declare no conflict of interest.

\section{References}

1. Camm AJ, Kirchhof P, Lip GY, et al. The Task Force for the Management of Atrial Fibrillation of the European Society of Cardiology (ESC). Guidelines for the management of atrial fibrillation. Eur Heart J 2010; 31: 2369-429.

2. Wolf PA, D'Agostino RB, Belanger AJ, et al. Atrial fibrillation as an independent risk factor for stroke: the Framingham Study. Stroke 1991; 22: 983-8.

3. Hansen ML, Sørensen R, Clausen MT, et al. Risk of bleeding with single, dual, or triple therapy with warfarin, aspirin, and clopidogrel in patients with atrial fibrillation. Arch Intern Med 2010; 170: 1433-41.

4. Lip GY, Huber K, Andreotti F, et al. Management of antithrombotic therapy in atrial fibrillation patients presenting with acute coronary syndrome and/or undergoing percutaneous coronary intervention/stenting. Thromb Haemost 2010; 103: 13-28.

5. Roffi M, Patrono C, Collet JP, et al. 2015 ESC Guidelines for the management of acute coronary syndromes in patients presenting without persistent ST-segment elevation Task Force for the Management of Acute Coronary Syndromes in Patients Presenting without Persistent ST-Segment Elevation of the European Society of Cardiology (ESC). Eur Heart J 2016; 37: 267-315.

6. Lip GY, Nieuwlaat R, Pisters R, et al. Refining clinical risk stratification for predicting stroke and thromboembolism in atrial fibrillation using a novel risk factor-based approach: the euro heart survey on atrial fibrillation. Chest 2010; 137: 263-72.

7. Schulman S, Kearon C; Subcommittee on Control of Anticoagulation of the Scientific and Standardization Committee of the International Society on Thrombosis and Haemostasis. Definition of major bleeding in clinical investigations of antihemostatic medicinal products in non-surgical patients. J Thromb Haemost 2005; 3: 692-4.

8. Lip GY, Windecker S, Huber K, et al. Management of antithrombotic therapy in atrial fibrillation patients presenting with acute coronary syndrome and/or undergoing percutaneous coronary or valve interventions: a joint consensus document of the European Society of Cardiology Working Group on Thrombosis, European Heart Rhythm Association (EHRA), European Association of Percutaneous Cardiovascular Interventions (EAPCI) and European Association of Acute Cardiac Care (ACCA) endorsed by the Heart Rhythm Society (HRS) and Asia-Pacific Heart Rhythm Society (APHRS). Eur Heart J 2014; 35: 3155-79.

9. Cho JR, Angiolillo DJ. Percutaneous coronary intervention and atrial fibrillation: the triple therapy dilemma. J Thromb Thrombolysis 2015; 39: 203-8.

10. Beyer-Westendorf J, Förster K, Pannach S, et al. Rates, management, and outcome of rivaroxaban bleeding in daily care: results from the Dresden NOAC registry. Blood 2014; 124 : 955-62.

11. Thygesen K, Alpert JS, White HD. Universal definition of myocardial infarction. Eur Heart J 2007; 28: 2525-38.

12. Cutlip DE, Windecker S, Mehran R, et al. Clinical end points in coronary stent trials: a case for standardized definitions. Circulation 2007; 115: 2344-51.

13. Rubboli A, Halperin JL, Airaksinen KE, et al. Antithrombotic therapy in patients treated with oral anticoagulation undergoing coronary artery stenting. An expert consensus document with focus on atrial fibrillation. Ann Med 2008; 40: 428-36.

14. Faxon DP, Eikelboom JW, Berger PB, et al. Consensus document: antithrombotic therapy in patients with atrial fibrillation undergoing coronary stenting. A North-American perspective. Thromb Haemost 2011; 106: 572-84.

15. Jamula E, Lloyd NS, Schwalm JD, et al. Safety of uninterrupted anticoagulation in patients requiring elective coronary angiography with or without percutaneous coronary intervention: a systematic review and metaanalysis. Chest 2010; 138: 840-7.

16. Steg PG, James SK, Atar D, et al. ESC Guidelines for the management of acute myocardial infarction in patients presenting with ST-segment elevation. Eur Heart J 2012; 33: 2569-619.

17. Hamm CW, Bassand JP, Agewall S, et al. ESC Guidelines for the management of acute coronary syndromes in patients presenting without persistent ST-segment elevation. Eur Heart J 2011; 32: 2999-3054.

18. Dzeshka MS, Brown RA, Lip GY. Patients with atrial fibrillation undergoing percutaneous coronary intervention. Current concepts and concerns: part I. Pol Arch Med Wewn 2015; 125: 73-81.

19. Farooq V, Gogas BD, Serruys PW. Restenosis: delineating the numerous causes of drug-eluting stent restenosis. Circ Cardiovasc Interv 2011; 4: 195-205.

20. Naber CK, Urban P, Ong PJ, et al. Biolimus-A9 polymer-free coated stent in high bleeding risk patients with acute coronary syndrome: a Leaders Free ACS sub-study. Eur Heart J 2016 May 17, [Epub ahead of print] DOI: 10.1093/eurheartj/ehw203.

21. Steg G, James S, Atar D, et al. ESC Guidelines for the management of acute myocardial infarction in patients presenting with ST-segment elevation. Eur Heart J 2012; 33: 2569-619.

22. Faza NN, Mentias A, Parashar A, et al. Bleeding complications of triple antithrombotic therapy after percutaneous coronary interventions. Catheter Cardiovasc Interv 2016 May 24 [Epub ahead of print] DOI: $10.1002 /$ ccd.26574.

23. D'Ascenzo F, Taha S, Moretti C, et al. Meta-analysis of randomized controlled trials and adjusted observational results of use of clopidogrel, aspirin, and oral anticoagulants in patients undergoing percutaneous coronary intervention. Am J Cardiol 2015; 115: 1185-93.

24. Hess CN, Peterson ED, Peng SA, et al. Use and outcomes of triple therapy among older patients with acute myocardial infarction and atrial fibrillation. J Am Coll Cardiol 2015; 66: 616-27.

25. Sørensen R, Hansen ML, Abildstrom SZ, et al. Risk of bleeding in patients with acute myocardial infarction treated with different combinations of aspirin, clopidogrel, and vitamin $\mathrm{K}$ antagonists in Denmark: a retrospective analysis of nationwide registry data. Lancet 2009; 374: 1967-74.

26. Koskinas KC, Räber L, Zanchin T, et al. Clinical impact of gastrointestinal bleeding in patients undergoing percutaneous coronary interventions. Circ Cardiovasc Interv 2015; 8: e002053.

27. Marin F, Huber K, Lip GY. Antithrombotic therapy in atrial fibrillation and stent implantation: treatment or threats by the use 
of triple or dual antithrombotic therapy. Thromb Haemost 2013; 110: 623-5.

28. Undas A. Fibrin clot properties and their modulation in thrombotic disorders. Thromb Haemost 2014; 112: 32-42.

29. Wysokinski WE, Owen WG, Fass DN, et al. Atrial fibrillation and thrombosis: immunohistochemical differences between in situ and embolized thrombi. J Thromb Haemost 2004; 2: 1637-44.

30. Stepien E, Kablak-Ziembicka A, Musialek P, et al. Fibrinogen and carotid intima media thickness determine fibrin density in different atherosclerosis extents. Int J Cardiol 2012; 157: 411-3.

31. Winter MP, Koziński M, Kubica J, et al. Personalized antiplatelet therapy with P2Y12 receptor inhibitors: benefits and pitfalls. Post Kardiol Interw 2015; 11: 259-80.

32. Connolly S, Ezekowitz, M, Yusuf S, et al. Dabigatran versus warfarin in patients with atrial fibrillation. N Engl J Med 2009; 361: 1139-51.

33. Patel MR, Mahaffey KW, Garg J, et al. Rivaroxaban versus warfarin in nonvalvular atrial fibrillation. N Engl J Med 2011; 365: 883-91.

34. Cho JR, Angiolillo DJ. Percutaneous coronary intervention and atrial fibrillation: the triple therapy dilemma. J Thromb Thrombolysis 2015; 39: 203-8. 